\title{
RESEARCH
}

Open Access

\section{The relationship between physical activity, mental wellbeing and symptoms of mental health disorder in adolescents: a cohort study}

\author{
Sarah Louise Bell ${ }^{1 *}$, Suzanne Audrey ${ }^{1}$, David Gunnell ${ }^{1,2}$, Ashley Cooper ${ }^{2,3}$ and Rona Campbell ${ }^{1}$
}

\begin{abstract}
Background: Mental illness is a worldwide public health concern. In the UK, there is a high prevalence of mental illness and poor mental wellbeing among young people. The aim of this study was to investigate whether physical activity is associated with better mental wellbeing and reduced symptoms of mental health disorder in adolescents.

Methods: A cohort of 928 12-13 year olds (Year 8) from six secondary schools in England, who had participated in the AHEAD trial, 'Activity and Healthy Eating in Adolescence', were followed up three years later (when 15-16 years old, Year 11). At baseline, physical activity was measured using accelerometers. At follow-up, mental wellbeing was measured using the 'Warwick Edinburgh Mental Wellbeing Scale' (WEMWBS) and symptoms of mental health disorder using the 'Strengths and Difficulties Questionnaire' (SDQ). Multivariable linear regression analyses were used to investigate associations between physical activity and both mental wellbeing and symptoms of mental health disorder.

Results: 794 (86\%) of the eligible 928 young people provided valid accelerometer data at baseline. 668 (72\%) provided complete mental wellbeing data and 673 (73\%) provided complete symptoms of mental health disorder data at follow-up. The multivariable analyses showed no evidence of an association between physical activity volume (counts per minute (cpm)) or intensity (Moderate to Vigorous Physical Activity (MVPA)) and mental wellbeing (WEMWBS overall score) or overall symptoms of mental health disorder (SDQ Total Difficulties Score). However, higher levels of physical activity volume at age 12-13 years were associated with lower scores on the emotional problems subscale of the SDQ at age 15-16 years.

Conclusions: This cohort study found no strong evidence that physical activity is associated with better mental wellbeing or reduced symptoms of mental health disorder in adolescents. However, a protective association between physical activity and the emotional problems subscale of the SDQ was found. This suggests that physical activity has the potential to reduce symptoms of depression and anxiety in adolescents. Future cohort study designs should allow for repeated measures to fully explore the temporal nature of any relationship.
\end{abstract}

Keywords: Physical activity, Mental wellbeing/mental health/mental illness/mental health disorder, Adolescents/ young people, Cohort study

\footnotetext{
* Correspondence: s.bell@bristol.ac.uk

'Population Health Sciences, Bristol Medical School, University of Bristol,

Bristol BS8 2PS, UK

Full list of author information is available at the end of the article
}

(c) The Author(s). 2019 Open Access This article is distributed under the terms of the Creative Commons Attribution 4.0 International License (http://creativecommons.org/licenses/by/4.0/), which permits unrestricted use, distribution, and reproduction in any medium, provided you give appropriate credit to the original author(s) and the source, provide a link to the Creative Commons license, and indicate if changes were made. The Creative Commons Public Domain Dedication waiver (http://creativecommons.org/publicdomain/zero/1.0/) applies to the data made available in this article, unless otherwise stated. 


\section{Background}

Mental illness is a worldwide public health concern [1]. It is currently the largest single cause of disability in the UK representing an estimated $28 \%$ of the total disease burden (compared to 16\% each for cancer and heart disease) [2]. The World Health Organization (2013) estimates that, worldwide, $20 \%$ of adolescents in any given year may experience mental illness. In England, the most recent population survey (2017) reported $14.4 \%$ ( 1 in 7 ) of young people aged 11-16 years were identified with a mental health disorder [3]. Emotional disorders (present in 9\%) were the most common type at this age followed by behavioural (conduct) disorders (6.2\%) [3]. Mental health disorder has diverse and long-term negative effects on individuals, their families, and wider society [4].

Population surveys have also found increased levels of low wellbeing in young people [3]. Mental wellbeing is conceptualised as more than the absence of mental illness [5]. It has been described as encompassing hedonic (happiness, life satisfaction, and affect) and eudaimonic (positive functioning, sense of purpose, and self-acceptance) wellbeing [6-10]. Mental wellbeing is protective for a range of health outcomes [11-14] and found to be associated with higher educational outcomes in adolescence and better occupational functioning in adulthood [15-17]. Correlates of young peoples' mental illness and mental wellbeing are reported to be largely distinct, stressing the importance of considering these concepts separately and avoiding their conflation [18].

While mental illness and mental wellbeing may be related, they are not necessarily distinct ends of a continuum [19-21]. The dual continuum model views mental illness (or mental health disorder) and mental health (or mental wellbeing) as two separate continua rather than as opposite ends of the same continuum [20]. Keyes and Lopez (2002) depicted the dual continuum model of mental illness and mental health and described four states: struggling (incomplete mental illness i.e. mental illness and high wellbeing), floundering (complete mental illness i.e. mental illness and low wellbeing), languishing (incomplete mental health i.e. no mental illness and low wellbeing), and flourishing (complete mental health i.e. no mental illness and high wellbeing). A large number of adolescents are thought to suffer from poor mental wellbeing despite being free from mental illness $[4,22]$. Therefore, promoting mental wellbeing alongside preventing and treating the symptoms of mental illness, is a growing priority. The recent Green Paper (2018) focuses on schools finding low cost and low risk interventions to promote mental wellbeing and prevent symptoms of mental health disorder [23].

Although there is evidence of physical activity improving mental wellbeing $[24,25]$ and having the potential to prevent symptoms of mental health disorder [26, 27] in adults, the evidence of any relationship in adolescents is weaker. The studies lack measurement consistency, having defined and assessed physical activity, mental wellbeing, and symptoms of mental health disorder in a variety of ways. Furthermore, few studies have used a multi-dimensional measure of mental wellbeing or symptoms of mental health disorder (most capture only one component of mental wellbeing such as self-esteem [28] or self-efficacy [29] or a specific mental health problem such as depression [30-34]), and studies that have used an objective measure of physical activity to assess any relationship are limited [35-37].

Several reviews have attempted to analyse any association in young people [38-51]. A review of reviews by Biddle et al. (2011) [48] showed that physical activity has beneficial effects on mental health in children and adolescents. More recently there has been a significant increase in the number and quality of studies exploring any association, and when the review of reviews was updated in 2019 [49], physical activity continued to be shown to be associated with certain mental health outcomes in young people (a causal association was found with cognitive functioning, a partial association for depression, no association for self-esteem, and research focusing on the association of physical activity with anxiety was reported to be variable but generally showed small beneficial effects) [49]. A review by RodriguezAyllon et al. (2019) [50] analysed the effects of physical activity interventions (randomised controlled trials and non-randomised controlled trials) on mental health outcomes of adolescents and also synthesised the observational evidence (both longitudinal and cross-sectional). Their review included studies that had at least one 'psychological illbeing' (i.e. depression, anxiety, stress or negative effect) and/or 'psychological wellbeing' (self-esteem, self-concept, self-efficacy, self-image, positive affect, optimism, happiness and satisfaction with life) outcome. They concluded that there was a small positive effect of physical activity interventions on mental health outcomes in adolescents [50].

The SDQ is a unique screening tool of symptoms indicating overall mental health disorder in young people. This composite measure identifies symptoms of emotional problems, hyperactivity, and behavioural/conduct problems and has been used in the UK series of surveys of the mental health of children and young people (1999, 2004 and 2017) [3] alongside other significant population surveys [52]. Despite this, few studies have used this measure when looking at the association between physical activity and symptoms of mental health disorder [31, 53-55]. Of the studies identified, neither of the two longitudinal studies used an objective measure of physical activity $[31,53]$. 
The WEMWBS is a relatively new scale, also used in the series of surveys in the UK [3], designed to capture population mental wellbeing. The reviews that have included studies assessing the relationship between physical activity and various aspects of mental wellbeing [38-44; 46-50] have concluded that there is evidence of promise, but further studies are needed that use a multi-dimensional measure such as the WEMWBS.

Given the limitations of the evidence base, the aim of this study was to determine whether physical activity is associated with mental wellbeing and symptoms of mental health disorder in adolescents. This is the first study to investigate any potential relationship longitudinally using an objective measure of physical activity and valid and reliable self-report measures of both mental wellbeing, using the WEMWBS, and symptoms of mental health disorder, using the SDQ, in adolescents.

\section{Methods}

A prospective cohort was formed based on the 928 participants from six secondary schools in the South West of England who took part in a two-year school-based exploratory randomised controlled trial (RCT) of an Activity and Healthy Eating intervention for use in ADolescence: the AHEAD trial [56]. All state secondary schools in the selected local authorities were invited to participate in the study. Schools first to express an interest (ensuring variation in size, geographical area, Ofsted rating, Free School Meal entitlement, and achievement rating) were recruited to the study. Physical activity was measured in 2008 when the participants were aged 1213 years (Year 8); mental wellbeing and symptoms of mental health disorder was measured three years later (2011) when the participants were aged 15-16 years (Year 11). The inclusion criteria were participation in the AHEAD trial and continued attendance at a study school three years later. Data collections at baseline (2008) and follow-up (2011) were conducted by a team of researchers in the schools (classrooms or school halls) during a usual lesson (approximately $60 \mathrm{~min}$ ). There was no evidence of promise that the AHEAD intervention improved physical activity or diet.

\section{Physical activity measure}

The ActiGraph GT1M accelerometer (ActiGraph, LLC, Penscola, FL) was used to measure physical activity. Participants were instructed in the use of the accelerometers in school, and then asked to wear the instrument for seven days during waking hours, except for water-based activities such as bathing and swimming. Accelerometer data were downloaded using ActiLife software (Lifestyle Monitor System software Version 3.3.0) and processed using Kinesoft software (Version 3.3.62; Kinesoft, Saskatchewan,
Canada) to generate outcome variables (10 s epochs were used to capture the sporadic nature of adolescent physical activity). Physical activity volume was computed as mean accelerometer counts per minute (cpm), and physical activity intensity (mean minutes per day of Moderate to Vigorous Physical Activity (MVPA)) was computed using established thresholds [57]. A valid day of measurement was defined as recording at least $480 \mathrm{~min}(8 \mathrm{~h})$ of data (monitoring period from $7 \mathrm{am}$ until $11 \mathrm{pm}$; periods of $\geq 60 \mathrm{~min}$ of consecutive zeros, with allowance for $2 \mathrm{~min}$ of interruption, was classed as nonwear time) and at least three valid days were required for inclusion in analyses.

\section{Mental wellbeing and symptoms of mental health disorder measures}

The 'Warwick Edinburgh Mental Wellbeing Scale' (WEMWBS) [58], validated for use in adolescents aged 13-16 years, was used to measure mental wellbeing. The WEMWBS has 14 positively worded items with a fivepoint Likert scoring scale for each item (with scores ranging from $1=$ none of the time to $5=$ all of the time). The responses to each item were summed to give an overall WEMWBS score; a minimum score of 14 (i.e. poor mental wellbeing) and a maximum of 70 (i.e. good mental wellbeing). The higher score, indicative of better mental wellbeing, reflects more positive thoughts, feelings and behaviours. Where scores for three or less items were missing the mean value of responses for completed items for that individual was used to replace the score for missing items, enabling a total score for that individual to be computed [59]. If more than three items were missing the data for that participant were not used. The WEMWBS was selected due to it being the first multi-dimensional scale to measure population mental wellbeing in adolescents, based on established indicators. It covers most aspects of mental wellbeing including both hedonic and eudaimonic perspectives and is suitable for looking at the relationship between physical activity and mental wellbeing.

The 'Strengths and Difficulties Questionnaire' (SDQ) [60] was used to measure symptoms of mental health disorder. It is a behavioural screening tool used to assess social, emotional, and physical aspects of behaviour in young people [61] and has been shown to be valid and reliable for completion by $11-16$ year olds [62]. The questionnaire has 25 items which comprise five subscales: (i) emotional symptoms (anxiety and depressive symptoms); (ii) conduct problems; (iii) hyperactivity/inattention; (iv) peer relationship problems; and (v) prosocial behaviour (positive behaviours such as being kind and helpful, scored in reverse of the other subscales). Response options are 'not true, somewhat true, or certainly 
true' (scored 0, 1 or 2). The SDQ 'Total Difficulties Score' (SDQ TDS) was generated by adding together the scores from the first four subscales and can range from 0 (low difficulties) to 40 (high difficulties). The five subscales whose scores can vary from 0 to 10 were also investigated independently. Items scores which were missing were imputed only if at least three out of five items were complete on each subscale. In this case the total subscale score for each participant was divided by the number of complete items to get the mean score and used to replace the missing item score $[60,63]$. If more than two items were missing from any sub scale the data for that subscale for that participant were not used. Participants required a score for each of the SDQ subscales to be able to compute their SDQ TDS. The SDQ was selected as the SDQ TDS provides a useful indicator of the level of symptoms of mental health disorder overall. Furthermore, the subscale items may be used to indicate specific clinical disorders in adolescents: depression, anxiety, hyperactivity attention deficit disorder (ADHD) and behavioural/conduct disorder. The SDQ is a useful screening tool for identifying young people with raised scores thus potentially at risk.

\section{Possible confounders and mediators}

The self-report behavioural questionnaires recorded a number of potential confounders and mediators of any potential relationship: age; gender; ethnicity; socioeconomic status (SES) (measured using the 'Family Affluence Scale' FAS II [64]); study school; number of daylight minutes (a proxy for season); baseline symptoms of mental health disorder (SDQ TDS); sleep (frequency of feeling tired when going to school in the morning); number of friends; belonging to teams and clubs; smoking; drinking alcohol; and intervention arm of the AHEAD trial [56] (the participants were randomised into two groups - the intervention arm received a physical activity and healthy eating intervention and the control arm continued with usual practice).

Confounders included were determined by the construction of a directed acyclic graph (DAG) and the availability of relevant data on study participants. Accelerometer wear time was computed from the participants accelerometer data.

Data from the self-report behavioural questionnaires were entered into a secure Access database and the accelerometer data were stored as anonymised files on a secure drive. All analyses were conducted using Stata 13 MP [65].

\section{Statistical analysis}

The analyses assessed the association between physical activity and the measures of mental wellbeing and symptoms of mental health disorder. Multivariable linear regression analyses were used to estimate exposure effects controlling for potential confounders and mediators which were investigated by grouping them as clusters of related factors in the models: i.e. socioeconomic factors (ethnic group, SES, study school); factors that may influence the physical activity data processing (daylight minutes (when volume or MVPA exposure), minutes of wear time (when MPVA exposure only); lifestyle factors (sleep, friends, belonging to teams or clubs, drinking alcohol, smoking; measured at follow-up only); baseline symptoms of mental health disorder); and then by producing a fully adjusted model containing all of these factors. Where there was evidence of confounding or mediation (associations weakened or enhanced), further models were fitted to investigate this in more detail. Confounders adjusted for were determined by the availability of relevant data on study participants. This somewhat crude epidemiological approach was used due to there being no clear evidence of associations (and whether confounders or mediators in the relationship) in the literature. Coefficients represent the linear relationship- change in WEMWBS overall score, SDQ TDS or SDQ subscale score per unit increase in physical activity (volume or intensity). Physical activity volume was defined by accelerometer counts (a dimensionless output from the accelerometer) per minute of recording (computed as total counts recorded divided by the total minutes of valid recording over the measurement period, described as counts per minute ( $\mathrm{cpm})$ ), whilst physical activity intensity was defined as daily minutes of Moderate to Vigorous Physical Activity (MVPA). The relationship was quantified as the change in mental wellbeing or symptoms of mental health disorder score associated with an increase of $100 \mathrm{cpm}$ (e.g. an increase from 508 cpm to $608 \mathrm{cpm}$, an approximately $20 \%$ increase in physical activity volume from baseline mean of the sample); or an additional $60 \mathrm{~min}$ of daily MVPA. Tests for interactions were carried out to investigate whether observed associations differed by gender. There was no evidence that associations between physical activity (volume and MVPA) and either mental wellbeing or symptoms of mental health disorder (WEMWBS and SDQ) differed in males and females. The test for interaction $p$-value ranged from $p=0.19-0.97$ so all models were based on data for males and females combined.

\section{Ethics approval and consent to participate}

The University of Bristol Faculty of Medicine and Dentistry Ethics Committee gave full approval in 2007 for the AHEAD feasibility study and pilot trial (reference number 060702) and in 2011 for the cohort study (reference number 101119).

Consent procedures were the same in the original feasibility study and pilot trial and in the subsequent 
cohort study. Firstly, written consent to participation was sought from each schools' headteacher. Secondly, letters were posted by school staff to the parents/carers of all eligible school pupils explaining the study and enclosing a reply slip to be returned if parents/carers did not want their child to participate. This 'opt-out' method of consent has been found to be an ethical and appropriate procedure in low-risk prevention research and avoids the low response rates and potential sampling bias when opt-in parental consent procedures are used [66, 67]. At all data collections, the young people were provided with information about the study and informed that they could 'opt-out' of some or all the study activities at any point and were asked to sign individual assent forms.

\section{Results}

\section{Cohort study profile and baseline characteristics}

794 (86\%) of the 928 pupils provided complete, valid baseline physical activity data and were followed-up three years later to complete mental wellbeing and symptoms of mental health disorder measures. 673 (73\%) completed the SDQ and 668 (72\%) completed the WEMWBS at follow-up. Those lost to follow-up were more likely to be older, male and from one particular school (due to a new headteacher using alternative educational placements for a large number of the school's more challenging pupils). Table 1 shows the baseline characteristics of the participants included and excluded from the cohort. Figure 1 displays the study profile for the cohort study and Table 2 describes the baseline characteristics of the participants.

\section{Physical activity at baseline}

At baseline, overall physical activity volume (mean (SD) counts per minute (cpm)) was $508.3 \mathrm{cpm}(169.42)$ and participants recorded 55.6 (21.5) (mean (SD)) daily minutes of MVPA). Females were less active than males with regard to both physical activity volume (mean difference $86.39 \mathrm{cpm}$ (95\% CI $111.2 \mathrm{cpm}$ to $61.6 \mathrm{cpm}, p<$ 0.001 ) and intensity (mean difference $11.7 \mathrm{~min}(95 \% \mathrm{CI}$ -15.41 to -8.82$), \mathrm{p}<0.001)$.

\section{Mental wellbeing and symptoms of mental health disorder at follow-up}

There was a negative association between the WEMWBS overall score and the SDQ TDS $(r=-0.41)$ at follow-up. This relatively weak correlation indicates the scales are measuring different things (the WEMWBS overall score only accounts for $16 \%$ of the total variation in the SDQ TDS). At follow-up, the participants' WEMWBS overall mean (SD) score was 48.74 (8.66) (data from a similar study (13-16 year olds) 48.8 (8.66) [58]; females $(n=$ 342) 46.93 (8.90) and males $(n=326) 50.63$ (7.99) with strong evidence of a gender difference in WEMWBS overall score (mean difference in WEMWBS overall score -3.70 (95\% CI -4.99 to -2.24$) p<0.001)$. Females had a lower WEMWBS overall score indicating poorer mental wellbeing than males. The participants' SDQ TDS mean score was 12.17 (5.56) (normative data (for $11-15$ years) $10.3(5.2))$ [60]; females $(n=343) 12.66$ (5.36) and males $(n=330) 11.66$ (5.73). Again there was evidence of a gender difference in SDQ TDS (mean difference in SDQ TDS 1.00 (95\% CI 0.16 to 1.84 ) $p=$

Table 1 Baseline characteristics of participants included and excluded from the cohort study

\begin{tabular}{|c|c|c|c|c|}
\hline Baseline characteristics & & $\begin{array}{l}\text { Excluded }\left(n=242^{*}\right) \\
\mathrm{n}(\%)\end{array}$ & $\begin{array}{l}\text { Included }(n=673) \\
\mathrm{n}(\%)\end{array}$ & $\begin{array}{l}\text { Difference in proportion between } \\
\text { excluded versus included categories** }\end{array}$ \\
\hline \multirow[t]{2}{*}{ Gender } & Males & $149(31.1)$ & $330(68.9)$ & $X^{2}=11.21(p=0.001)$ \\
\hline & Females & $93(21.0)$ & $343(79.0)$ & \\
\hline \multirow[t]{2}{*}{ Ethnicity } & White & $217(25.7)$ & $629(74.3)$ & $X^{2}=3.67(p=0.06)$ \\
\hline & Other & $25(36.0)$ & $44(64.0)$ & \\
\hline \multirow[t]{2}{*}{ FAS } & Low and medium (0-5) & $121(25.5)$ & $353(74.5)$ & $X^{2}=2.09(p=0.15)$ \\
\hline & High (6-9) & $87(21.4)$ & $320(87.6)$ & \\
\hline \multirow[t]{6}{*}{ Study school } & 1 & $40(22.0)$ & $142(78.0)$ & $X^{2}=78.04(p<0.001)$ \\
\hline & 2 & $58(33.3)$ & $116(66.7)$ & \\
\hline & 3 & $31(18.8)$ & $134(81.2)$ & \\
\hline & 4 & $15(15.6)$ & $81(84.4)$ & \\
\hline & 5 & $28(16.5)$ & $142(83.5)$ & \\
\hline & 6 & $70(54.7)$ & $58(45.3)$ & \\
\hline \multirow[t]{2}{*}{ Physical activity*** } & Volume (mean counts per minute) & $482.78(158.12)$ & $508.28(169.42)$ & $-25.5(95 \% \mathrm{Cl}-58.02$ to 7.02$) p=0.12$ \\
\hline & MVPA (mean daily MVPA minutes) & $51.90(21.66)$ & $55.59(21.47)$ & $-3.69(95 \% \mathrm{Cl}-7.86$ to 0.48$) p=0.08$ \\
\hline
\end{tabular}

*13 pupils were excluded but did not have baseline characteristics data to compare

**Pearson's chi-squared tests

***Physical activity measures in excluded group $n=121$ due to missing data (t-test mean difference) 


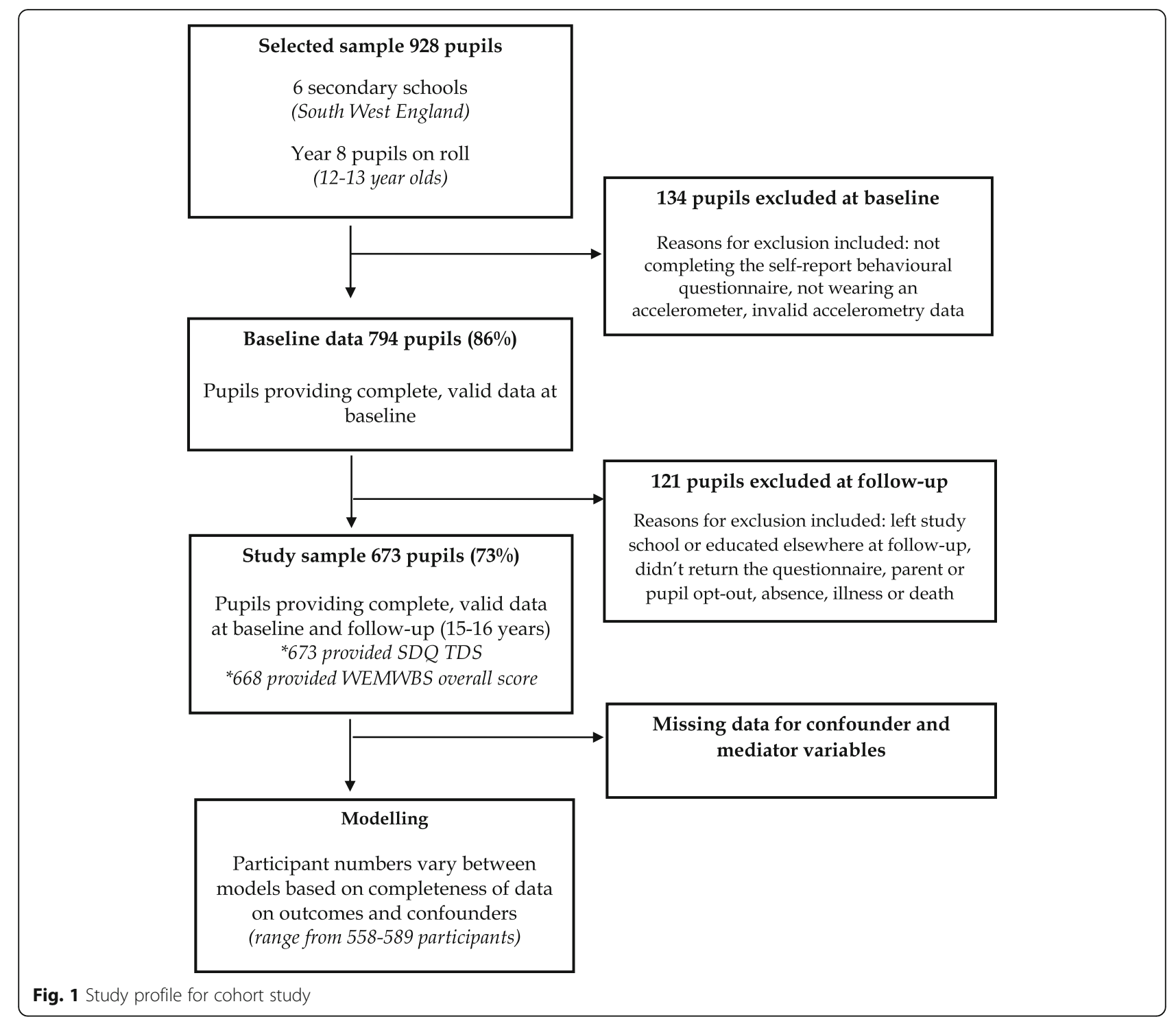

0.02). Females had a higher SDQ TDS indicating higher symptoms of mental health disorder than males.

\section{Main findings}

The univariable (adjusted for gender, age and intervention arm of the AHEAD trial) and multivariable analyses showed no evidence of an association between physical activity (volume or intensity) and mental wellbeing (WEMWBS overall score) or overall symptoms of mental health disorder (SDQ TDS) (Table 3). When the five SDQ subscales were analysed independently, an association was found between both physical activity volume and intensity and the emotional problems subscale of the SDQ (scale range 0-10). However, the association found between MVPA and the emotional problems subscale of the SDQ was slightly attenuated in the fully adjusted model (when controlling for symptoms of mental health disorder at baseline (SDQ TDS)), such that confidence intervals included the null value.

For physical activity volume, a mean increase of 100 cpm ( 20\% increase in physical activity volume) was associated with a decrease in the emotional problems subscale score of 0.12 (unadjusted model) and 0.11 (fully adjusted model). The confidence intervals (95\% CI) ranged from -0.23 to -0.00 in the fully adjusted model implying that a potential reduction in the emotional problems subscale score of 0.23 could be achieved with an additional 100 mean cpm of physical activity (the extreme end of the effect estimate). For physical activity intensity, an additional $60 \mathrm{~min}$ of mean daily MVPA was associated with a decrease in the emotional problems subscale score of 0.54 (unadjusted model) and 0.49 (fully adjusted model; however confidence intervals crossed zero). 
Table 2 Baseline characteristics of participants in the cohort study

\begin{tabular}{|c|c|c|c|c|c|c|}
\hline \multirow[t]{2}{*}{ Continuous variables } & \multicolumn{2}{|l|}{ All } & \multicolumn{2}{|l|}{ Females } & \multicolumn{2}{|l|}{ Males } \\
\hline & $\mathrm{n}$ & Mean (SD) & $\mathrm{n}$ & Mean (SD) & $\mathrm{n}$ & Mean (SD) \\
\hline Age in years & 673 & $12.69(0.34)$ & 343 & $12.68(0.34)$ & 330 & $12.70(0.34)$ \\
\hline SDQ Total Difficulties Score (SDQ TDS) & 637 & $12.41(5.76)$ & 328 & $12.33(5.67)$ & 309 & $12.50(5.87)$ \\
\hline Physical activity volume (mean counts per minute (cpm)) & 673 & $508.28(169.42)$ & 343 & $465.93(153.25)$ & 330 & $552.31(174.35)$ \\
\hline Physical activity intensity (mean daily MVPA minutes) & 673 & $55.59(21.47)$ & 343 & $49.85(19.24)$ & 330 & $61.56(22.07)$ \\
\hline \multirow[t]{2}{*}{ Categorical variables } & $\mathbf{n}$ & Category & All & Females & Males & \\
\hline & & & n (\%) & n (\%) & n (\%) & \\
\hline Gender & 673 & & & $343(51.0)$ & $330(49.0)$ & \\
\hline \multirow[t]{2}{*}{ Ethnicity } & 673 & White & $629(93.0)$ & $320(93.3)$ & 309 (93.6) & \\
\hline & & Other & $44(7.0)$ & $23(6.7)$ & $21(6.4)$ & \\
\hline \multirow[t]{2}{*}{ Family Affluence Scale (SES) } & 673 & Low and Med (0-5) & $353(52.0)$ & $187(54.5)$ & $166(50.3)$ & \\
\hline & & High (6-9) & $320(48.0)$ & $156(45.5)$ & $164(49.7)$ & \\
\hline \multirow[t]{6}{*}{ Study school } & 673 & 1 & $142(21.0)$ & $79(23.0)$ & $63(19.1)$ & \\
\hline & & 2 & $116(17.0)$ & $64(18.7)$ & $52(15.8)$ & \\
\hline & & 3 & $134(20.0)$ & $62(18.1)$ & $72(21.8)$ & \\
\hline & & 4 & $81(12.0)$ & $41(12.0)$ & $40(12.1)$ & \\
\hline & & 5 & $142(21.0)$ & $59(17.2)$ & $83(25.2)$ & \\
\hline & & 6 & $58(9.0)$ & $38(11.1)$ & $20(6.1)$ & \\
\hline \multirow[t]{2}{*}{ Intervention arm of the AHEAD trial } & 673 & Intervention & $339(50.4)$ & $184(54.3)$ & $155(45.7)$ & \\
\hline & & Control & $334(49.6)$ & $159(47.6)$ & $175(52.4)$ & \\
\hline \multirow[t]{2}{*}{ Sleep } & 665 & Good sleep & $348(52.0)$ & $169(50.0)$ & $179(55.0)$ & \\
\hline & & Poor sleep & $317(48.0)$ & $172(50.0)$ & $145(45.0)$ & \\
\hline \multirow[t]{2}{*}{ Smoking } & 667 & Yes & $115(17.0)$ & $71(20.9)$ & $44(13.5)$ & \\
\hline & & No & $552(83.0)$ & $269(79.1)$ & $283(86.5)$ & \\
\hline \multirow[t]{4}{*}{ Drinking alcohol } & 603 & Don't drink & $29(4.8)$ & $11(3.5)$ & $18(6.2)$ & \\
\hline & & Occasional & $352(58.4)$ & $198(63.7)$ & $154(52.7)$ & \\
\hline & & Weekly & $176(29.2)$ & $84(27.0)$ & $92(31.5)$ & \\
\hline & & Frequent & $46(7.6)$ & $18(5.8)$ & $28(9.6)$ & \\
\hline \multirow[t]{4}{*}{ Number of friends } & 663 & None & $4(0.6)$ & $0(0.0)$ & $4(1.2)$ & \\
\hline & & $1-2$ & $67(10.1)$ & $33(9.7)$ & $34(10.5)$ & \\
\hline & & $3-6$ & $250(37.7)$ & $133(39.1)$ & $117(36.2)$ & \\
\hline & & 7 or more & $342(51.6)$ & $174(51.2)$ & $168(52.0)$ & \\
\hline \multirow[t]{2}{*}{ Belonging to teams or clubs } & 666 & Yes & $321(48.2)$ & $135(39.6)$ & $186(57.2)$ & \\
\hline & & No & 345 (51.8) & $206(60.4)$ & 139 (42.8) & \\
\hline
\end{tabular}

\section{Discussion}

\section{Main findings}

To the best of our knowledge, this is the first longitudinal study to investigate the relationship between physical activity, mental wellbeing and symptoms of mental health disorder in adolescents. We also believe this is the first study to use an objective measure of physical activity (accelerometers) and composite measures of both mental wellbeing (WEMWBS) and symptoms of mental health disorder (SDQ) validated for use with young people alongside each other, to investigate any potential associations. We found no evidence of an association between physical activity (volume or MVPA) and mental wellbeing (WEMWBS overall score) or overall symptoms of mental disorder (SDQ TDS). However, a protective association was found between physical activity volume and the emotional problems subscale of the SDQ. This finding suggests that increasing physical activity volume in adolescents may have the potential to reduce their risk of emotional problems (items on the 


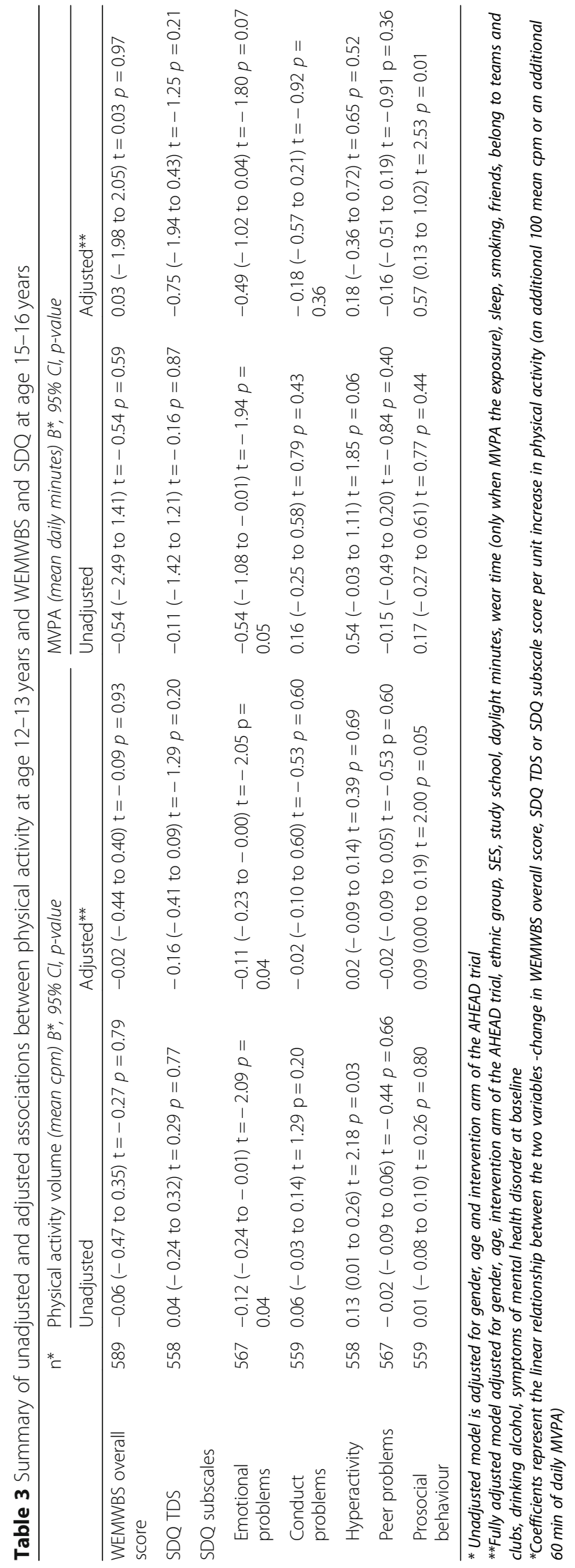


SDQ emotional problems subscale include: worrying a lot; having fears and being easily scared; being nervous in new situations and easily losing confidence; often feeling unhappy, down-hearted or tearful; and getting a lot of headaches, stomach-aches or sickness). Those adolescents accumulating more daily MVPA minutes may have more beneficial effects. Physical activity could provide an acceptable, low risk and cost-effective intervention for young people showing symptoms of depression and anxiety.

\section{Strengths and limitations of the study}

The study was based on a relatively large number of secondary school pupils drawn from six schools of different sizes and characteristics (e.g. rural schools, inner city schools) [56, 68]; participants are likely to be broadly representative of secondary school pupils in England. Loss to follow-up was largely due to participants no longer attending a study school and this is unlikely to have biased the patterns of associations found.

A strength of this study was its use of accelerometers, which provide an objective measure of physical activity increasing the precision of measurement. However, it is important to note that accelerometers have known limitations such as not accurately measuring cycling and not being waterproof, so do not measure physical activity from water-based activities.

This study contributes to the evolving debate concerning mental wellbeing and mental illness terminology and measurement. The findings from this study support the notion that mental wellbeing and symptoms of mental health disorder are two separate concepts, captured using different measurement scales. Using validated measures of both mental wellbeing and symptoms of mental health disorder was a strength and novel aspect of this study. This study demonstrated that physical activity is not associated with mental wellbeing or overall symptoms of mental health disorder, but has a protective relationship with regards to risk of emotional problems.

The cohort study would have benefited from repeated measures of physical activity, mental wellbeing and symptoms of mental health disorder, to fully explore the temporal nature of any relationship and take account of changing patterns of physical activity. If an effect of physical activity on mental wellbeing and symptoms of mental health disorder is short-lived, then a three-year time lag would be inappropriate to investigate any association [69].

We were able to control for a wide range of possible confounders and assess the effect of possible mediators of the relationship. However, some confounders were only measured at follow-up (sleep, number of friends, smoking, drinking alcohol, belonging to teams and clubs). The possible effects of some of the confounders may be different at baseline and follow-up (e.g. smoking and drinking behaviours would be more common at follow-up). Due to the WEMWBS not being available at the time of baseline measures, the SDQ TDS was used to control for baseline wellbeing. We were only able to adjust for confounders measured as part of the AHEAD trial. This study would have been strengthened if Body Mass Index (BMI) [70] and screen viewing behaviour [71] were measured and controlled for. The possible mechanisms underlying any association between physical activity, mental wellbeing and symptoms of mental health disorder in adolescents are complex [41]. It is possible that an integrative model that combined components of different hypotheses (biochemical e.g. release of endorphins, or psychosocial e.g. distraction, sense of mastery, social interaction) offers the most likely, full explanation [41]. Also, the effects may vary between individuals. Further research needs to consider confounding and mediating factors and exploration of potential mechanisms at the study design stage, to ensure candidate variables are measured appropriately.

\section{Findings in the context of existing research}

Studies that have explored the relationship between physical activity and symptoms of overall mental health disorder (using the SDQ) are scarce, and of those identified, no association was reported overall [31; 53-55]. However, Sagatun et al. (2007) [53] found that for males (but not females) the number of weekly hours (self-reported weekly hours of physical activity that makes them breathless) the boys spent on physical activity per week at age 15-16 years was negatively associated with emotional problems and peer problems at age 18-19 years. Similarly, Wiles et al. (2008) [31] reported young people (aged 11-14 years) who met recommended levels for physical activity ( $1 \mathrm{~h}$ per day) had, on average, a score on the emotional problems sub-scale of the SDQ that was 0.29 units lower $(-0.29(95 \% \mathrm{CI}-0.61$ to 0.022$))$ at 1 year follow-up compared to those who did not undertake recommended levels of physical activity. The association found in our study between physical activity volume and the emotional problems subscale of the SDQ $(-0.11(95 \%$ CI -0.23 to -0.00$)$ ) (overall but not when gender stratified) is similar to the findings of both these studies, and supports evidence from the recent physical activity and mental health in young people reviews $[49,50]$.

As noted at the outset, there are no longitudinal studies or RCTs that have used a multi-dimensional scale to investigate the relationship between physical activity and mental wellbeing in adolescents with which to compare our findings. Reviews have suggested evidence of promise $[41,50]$ but studies included only used single component measures of mental wellbeing outcomes such as 
self-image, satisfaction with life and happiness. In the review of reviews by Biddle et al. (2019) [49] evidence for support of a causal relationship was reported for cognitive function outcome measures, as well as academic achievement and brain structure and function. Although showing an association between physical activity and cognitive function is important to emphasis the role of physical activity in schools, this literature needs to be considered alongside further studies using a composite measure of mental wellbeing.

\section{Implications}

There is no strong evidence of any relationship between physical activity, mental wellbeing and overall symptoms of mental health disorder in adolescents. However the findings from this study, together with that from two other studies, suggests a relationship between physical activity volume and emotional problems. Cohort studies, designed specifically to look at the relationship between physical activity and both mental wellbeing and symptoms of mental health disorder, are needed to confirm and explore any potential associations further. Measurement scales that focus on more than one aspect of mental health disorder or mental wellbeing should be used in population level school-based research, and both the SDQ and WEMWBS scales warrant further exploration. Alongside this literature, the association between physical activity and specific mental health disorders should continue to be explored. Measures that can confirm an International Statistical Classification of Diseases and Related Health Problems (ICD-10) or Diagnostic and Statistical Manual of Mental Disorders (DSM-5) diagnosis in young people, such as the DAWBA (Development and Well-being Assessment), should be considered. Further studies that focus on mental health disorders common in adolescents, other than anxiety and depression, are needed. An objective measure of physical activity used alongside a standardised self-report physical activity questionnaire may be the best approach to understand the context of the physical activity data (e.g. physical activity outdoors may be better for mental wellbeing and team sports may prevent a particular type of mental health disorder). It is important that the self-report measure of physical activity incorporates information on general daily living activities, such as walking to and from school or playing outdoors, and captures any relevant contextual information [70]. Future study designs should allow for repeated measures to fully explore the temporal nature of any relationship, take account of changing patterns of physical activity and look at short-term associations.

\section{Conclusions}

This cohort study provided no strong evidence that physical activity is a protective factor for mental wellbeing or symptoms of mental health disorder in adolescents, as measured by the WEMWBS overall score and SDQ TDS. There was, however, evidence of an association between physical activity volume and the emotional problems subscale of the SDQ. This indicates that emotional problems (such as symptoms of depression and anxiety) in adolescents could be reduced by increasing their physical activity levels.

\section{Abbreviations \\ AHEAD: Activity and Health Eating in ADolescence; BMI: Body Mass Index; Cl: Confidence Interval; CPM: Counts Per Minute; DAWBA: Development and Well-being Assessment; DSM-5: Diagnostic and Statistical Manual of Mental Disorders, Fifth Edition) FAS (Family Affluence Scale); ICD-10: International Statistical Classification of Diseases and Related Health Problems; \\ MVPA: Moderate to Vigorous Physical Activity; SD: Standard Deviation; SDQ TDS: Strengths and Difficulties Questionnaire Total Difficulties Score; \\ SDQ: Strengths and Difficulties Questionnaire; SES: Social Economic Status; WEMWBS: Warwick Edinburgh Mental Wellbeing Scale}

\section{Acknowledgements}

Thanks are due to the schools and young people involved as this research would not have been possible without their support and willing participation.

\section{Authors' contributions}

SB planned and carried out the study, conducted the data analysis and wrote the manuscript. DG and RC advised on the data analysis and reviewed the manuscript. SA led the AHEAD trial and reviewed the manuscript. AC advised on the physical activity measurement and analysis and reviewed the manuscript.

\section{Funding}

The AHEAD trial (during which the baseline data was collected) was funded by the Department of Health Policy Research Programme (Project Number 0600002). SB was funded by a doctoral research fellowship from the National Institute for Health Research (NIHR-DRF-2010-03-51) to complete the followup study. The work was undertaken with the support of The Centre for the Development and Evaluation of Complex Interventions for Public Health Improvement (DECIPHer), a UKCRC Public Health Research Centre of Excellence. Joint funding (MR/KO232331/1) from the British Heart Foundation, Cancer Research UK, Economic and Social Research Council, Medical Research Council, the Welsh Government and the Wellcome Trust, under the auspices of the UK Clinical Research Collaboration, is gratefully acknowledged. The funding sources were not involved in the design of the study and collection, analysis, and interpretation of data or in writing the manuscript. DG and $A C$ are supported by the NIHR Biomedical Research Centre at University Hospitals Bristol NHS Foundation Trust and the University of Bristol, England. The views expressed in this publication are those of the author(s) and not necessarily those of the NHS, the National Institute for Health Research or the Department of Health and Social Care.

\section{Availability of data and materials}

The datasets during and/or analysed during the current study are available from the corresponding author on reasonable request.

\section{Ethics approval and consent to participate}

The University of Bristol Faculty of Medicine and Dentistry Ethics Committee gave full approval in 2007 for the AHEAD feasibility study and pilot trial (reference number 060702) and in 2011 for the cohort study (reference number 101119).

Consent procedures were the same in the original feasibility study and pilot trial and in the subsequent cohort study. Firstly, written consent to participation was sought from each schools' headteacher. Secondly, letters were posted by school staff to the parents/carers of all eligible school pupils 
explaining the study and enclosing a reply slip to be returned if parents/ carers did not want their child to participate. This 'opt-out' method of consent has been found to be an ethical and appropriate procedure in lowrisk prevention research and avoids the low response rates and potential sampling bias when opt-in parental consent procedures are used [66, 67]. At all data collections, the young people were provided with information about the study and informed that they could 'opt-out' of some or all the study activities at any point and were asked to sign individual assent forms.

\section{Consent for publication}

Not applicable.

\section{Competing interests}

The authors declare that they have no competing interests. RC is an NIHR Senior Investigator and member of the NIHR-PHR research funding committee. SA is a member of the NIHR-PHR research finding committee.

\section{Author details \\ ${ }^{1}$ Population Health Sciences, Bristol Medical School, University of Bristol, Bristol BS8 2PS, UK. ${ }^{2}$ National Institute of Health Research Biomedical Research Centre at the University Hospitals Bristol NHS Foundation Trust, Bristol, UK. ${ }^{3}$ Centre for Exercise, Nutrition and Health Sciences, School for Policy Studies, University of Bristol, Bristol BS8 1TZ, UK.}

Received: 23 April 2019 Accepted: 12 December 2019 Published online: 26 December 2019

\section{References}

1. World Health Organization. The global burden of disease: 2004 update. Geneva; 2014

2. Ferrari A, Charlson F, Norman R, Patten S, Freedman G, Murray C, Vos T, Whiteford $\mathrm{H}$. Burden of depressive disorders by country, sex, age, and year: findings from the global burden of disease study 2010. PLoS med. 2013; 10(11):e1001547.

3. Sadler K, Vizard T, Ford T, Marcheselli F, Pearce N, Mandalia D, Davis J, Brodie E, Forbes N, Goodman A, Goodman R, McManus S. Mental health of children and young people in England, 2017. London: NHS digital; 2018.

4. Davies S. Annual report of the chief medical officer 2013, public mental health priorities: investing in the evidence. London: Department of Health; 2014.

5. Ryan RM, Deci EL. On happiness and human potentials: a review of research on hedonic and eudaimonic well-being. Annu Rev Psychol. 2001;52(1):14166. https://doi.org/10.1146/annurev.psych.52.1.141.f.

6. Pollard EL, Lee PD. Child well-being: a systematic review of the literature. Soc Indic Res. 2003:61(1):59-78.

7. Ryff CD. Happiness is everything, or is it? Explorations on the meaning of psychological well-being. J Pers Soc Psychol. 1989;57(6):1069.

8. Diener E, Suh E. Measuring quality of life: economic, social, and subjective indicators. Soc Indic Res. 1997:40(1-2):189-216.

9. Seligman ME. Authentic happiness: using the new positive psychology to realize your potential for lasting fulfilment: Simon and Schuster; 2004.

10. Foresight. Foresight mental capital and wellbeing project: final project report. London: The Government Office for Science; 2008.

11. National Statistics: The Scottish Health Survey 2008:ISBN 9780755981076. accessed 16/01/2011.

12. Davidson R. Well-being and affective style: neural substrates and biobehavioural correlates. Philosophical transactions of the Royal Society of London. Series B: Biological Sci. 2004;359(1449):1395-411.

13. Singh-Manoux A, Martikainen $P$, et al. What does self rated health measure? Results from the British Whitehall II and French Gazel cohort studies. J Epidemiol Community Health. 2006;60(4):364-9.

14. Keyes CL. The nexus of cardiovascular disease and depression revisited: the complete mental health perspective and the moderating role of age and gender. Aging Ment Health. 2004;8(3):266-74.

15. Stewart-Brown S. Promoting health in children and young people: identifying priorities. J R Soc Promot Health. 2005;125(2):61.

16. Barlow J, Underdown A. Promoting the social and emotional health of children: where to now? J R Soc Health. 2005;125(2):64-70.

17. Currie C, Roberts C, Settertobulte W, Morgan A, Smith R, Samdal O, Barnekow RV. Young People's health in context: health behaviour in school- aged children (HSBC) study: international report from the 2001/2002 survey. WHO Regional Office for Europe: Copenhagen; 2004.

18. Patalay P, Fitzsimons E. Correlates of mental illness and wellbeing in children: are they the same? Results from the UK millennium cohort study. J Am Acad Child Adolesc Psychiatry. 2016;55(9):771-83.

19. Tudor K. Mental health promotion: paradigms and practice: psychology press; 1996

20. Keyes CL. Lopez SJ. Toward a science of mental health. 2002:45-59.

21. Holder MD. Happiness in children: measurement, correlates and enhancement of positive subjective well-being. London: Springer Science and Business Media; 2012.

22. Roberts RE, Attkisson CC, Rosenblatt A. Prevalence of psychopathology among children and adolescents. Am J Psychiatr. 1998;155(6):715-25.

23. Department of Health and Social Care and Department for Education. Transforming children and young people's mental health provision: A green paper. London; 2018.

24. Scully D, Kremer J, Meade MM, Graham R, Dudgeon K. Physical exercise and psychological well being: a critical review. Br J Sports Med. 1998;32(2):111-20.

25. Fox KR. The influence of physical activity on mental well-being. Public Health Nutr. 1999;2(3a):411-8.

26. Paluska SA, Schwen TL. Physical activity and mental health. Sports Med. 2000;29(3):167-80

27. Cooney GM, Dwan K, Greig CA, Lawlor DA, Rimer J, Waugh FR, McMurdo M, Mead GE. Exercise for depression. Cochrane Database of Systematic Reviews 2013, Issue 9. Art. No.: CD004366. DOI: https://doi.org/10.1002/14651858. CD004366.pub6.

28. Tremblay MS, Inman JW, Willms JD. The relationship between physical activity, self-esteem, and academic achievement in 12-year-old children. Pediatr Exerc Sci. 2000;12(3):312-23.

29. Valois RF, Umstattd MR, Zullig KJ, Paxton RJ. Physical activity behaviors and emotional self-efficacy: is there a relationship for adolescents? J Sch Health. 2008:78(6):321-7.

30. Wiles NJ, Haase AM, Lawlor DA, Ness A, Lewis G. Physical activity and depression in adolescents: cross-sectional findings from the ALSPAC cohort. Soc Psychiatry Psychiatr Epidemiol. 2012;47(7):1023-33.

31. Wiles NJ, Jones GT, Haase AM, Lawlor DA, Macfarlane GJ, Lewis G. Physical activity and emotional problems amongst adolescents. Soc Psychiatry Psychiatr Epidemiol. 2008:43(10):765-72.

32. Motl RW, Birnbaum AS, Kubik MY, Dishman RK. Naturally occurring changes in physical activity are inversely related to depressive symptoms during early adolescence. Psychosom Med. 2004;66(3):336-42.

33. Birkeland MS, Torsheim T, Wold B. A longitudinal study of the relationship between leisure-time physical activity and depressed mood among adolescents. Psychol Sport Exerc. 2009:10(1):25-34.

34. Rothon C, Edwards P, Bhui K, Viner RM, Taylor S, Stansfeld SA. Physical activity and depressive symptoms in adolescents: a prospective study. BMC Med. 2010;8(1):32

35. Opdal IM, Morseth B, Handegård BH, Lillevoll K, Ask H, Nielsen CS, Horsch A, Furberg AS, Rosenbaum S, Rognmo K. Change in physical activity is not associated with change in mental distress among adolescents: the Troms $\varnothing$ study: fit futures. BMC Public Health. 2019;19(1):916.

36. Van Dijk ML, Savelberg HH, Verboon P, Kirschner PA, De Groot RH. Decline in physical activity during adolescence is not associated with changes in mental health. BMC Public Health. 2016;16(1):300.

37. Toseeb U, Brage S, Corder K, Dunn VJ, Jones PB, Owens $M$, et al. Exercise and depressive symptoms in adolescents: a longitudinal cohort study. JAMA Pediatr. 2014;168(12):1093-100.

38. Gruber JJ. Physical activity and self-esteem development in children: a metaanalysis. American Academy of Physical Education Papers. 1986;19:30-48.

39. Ekeland E, Heian F, Hagen KB, Abbott JM, Nordheim L. Exercise to improve selfesteem in children and young people. Cochrane Database Syst Rev. 2004;1.

40. Liu M, Wu L, Ming Q. How does physical activity intervention improve selfesteem and self-concept in children and adolescents? Evidence from a meta-analysis. PLoS One. 2015;10(8):e0134804.

41. Whitelaw S, Teuton J, Swift J, Scobie G. The physical activity-mental wellbeing association in young people: a case study in dealing with a complex public health topic using a 'realistic evaluation' framework. Ment Health Phys Act. 2010;3(2):61-6.

42. Burkhardt J, Brennan C. The effects of recreational dance interventions on the health and well-being of children and young people: a systematic review. Arts Health. 2012;4(2):148-61. 
43. Lees C, Hopkins J. Peer reviewed: effect of aerobic exercise on cognition, academic achievement, and psychosocial function in children: a systematic review of randomized control trials. Prev Chronic Dis. 2013;10.

44. Ferreira-Vorkapic C, Feitoza JM, Marchioro M, Simões J, Kozasa E, Telles S. Are there benefits from teaching yoga at schools? A systematic review of randomized control trials of yoga-based interventions. Evid Based Complement Alternat Med. 2015.

45. Larun L, Nordheim L, Ekeland E, Hagen K, Heian F. Exercise in prevention and treatment of anxiety and depression among children and young people. Cochrane Database Syst Rev. 2006;4.

46. Ahn SA, Fedewa J. Meta-analysis of the relationship between physical activity and mental health. J Pediatr Psychol. 2011;10:22-8.

47. Das JK, Salam RA, Lassi ZS, Khan MN, Mahmood W, Patel V, Bhutta ZA. Interventions for adolescent mental health: an overview of systematic reviews. J Adolesc Health. 2016 Oct 1;59(4):S49-60.

48. Biddle SJ, Asare M. Physical activity and mental health in children and adolescents: a review of reviews. British J Sports Med. 2011;45(11):886-95.

49. Biddle SJ, Ciaccioni S, Thomas G, Vergeer I. Physical activity and mental health in children and adolescents: an updated review of reviews and an analysis of causality. Psychol Sport Exerc. 2019 May 1;42:146-55.

50. Rodriguez-Ayllon M, Cadenas-Sanchez C, Estevez-Lopez F, Muñoz NE, MoraGonzalez J, Migueles JH, Molina-Garcia P, Henriksson H, Mena-Molina A, Martinez-Vizcaino V, Catena A. Role of physical activity and sedentary behavior in the mental health of preschoolers, children and adolescents: a systematic review and meta-analysis. Sports Med. 2019;16:1-28.

51. Caldwell DM, Davies SR, Hetrick SE, Palmer JC, Caro P, López-López JA, Gunnell D, Kidger J, Thomas J, French C, Stockings E. School-based interventions to prevent anxiety and depression in children and young people: a systematic review and network meta-analysis. Lancet Psychiatry. 2019;14.

52. Duinhof EL, Lek KM, de Looze ME, Cosma A, Mazur J, Gobina I, Wüstner A, Vollebergh WA, Stevens GW. Revising the self-report strengths and difficulties questionnaire for cross-country comparisons of adolescent mental health problems: the SDQ-R. Epidemiol psychiatric sci 2019 3:1-0.

53. Sagatun A, Søgaard AJ, Bjertness E, Selmer R, Heyerdahl S. The association between weekly hours of physical activity and mental health: a three-year follow-up study of 15-16-year-old students in the city of Oslo. Norway BMC Public Health. 2007;7(1):155.

54. Eather N, Morgan PJ, Lubans DR. Effects of exercise on mental health outcomes in adolescents: findings from the CrossFit ${ }^{\mathrm{TM}}$ teens randomized controlled trial. Psychol Sport Exerc. 2016;26:14-23.

55. Bunketorp Käll L, Malmgren H, Olsson E, Lindén T, Nilsson M. Effects of a curricular physical activity intervention on children's school performance, wellness, and brain development. J Sch Health. 2015;85(10):704-13.

56. Bell SL, Audrey S, Cooper AR, Noble S, Campbell R. Lessons from a peer-led obesity prevention programme in English schools. Health Promot Int. 2017; 32(2):250-9.

57. Evenson KR, Catellier DJ, Gill K, Ondrak KS, McMurray RG. Calibration of two objective measures of physical activity for children. J Sports Sci. 2008;26(14): 1557-65.

58. Clarke A, Friede T, Putz R, Ashdown J, Martin S, Blake A, et al. WarwickEdinburgh Mental Well-being Scale (WEMWBS): validated for teenage school students in England and Scotland. A mixed methods assessment. BMC Public Health. 2011;11(1):487.

59. Bartram DJ, Yadegarfar G, Sinclair JM, Baldwin DS. Validation of the Warwick-Edinburgh mental well-being scale (WEMWBS) as an overall indicator of population mental health and well-being in the UK veterinary profession. Vet J. 2011;187(3):397-8.

60. Goodman R. Youth in Mind 2010 http://www.sdqinfo.com/py/sdqinfo/c0.py. Accessed 09/02/2016.

61. Muris P, Meesters C, Eijkelenboom A, Vincken M. The self-report version of the strengths and difficulties questionnaire: its psychometric properties in 8to 13-year-old non-clinical children. Br J Clin Psychol. 2004;43(4):437-48.

62. Goodman R. Psychometric properties of the strengths and difficulties questionnaire. J Am Acad Child Adolesc Psychiatry. 2001;40(11):1337-45.

63. Goodman A, Lamping DL, Ploubidis GB. When to use broader internalising and externalising subscales instead of the hypothesised five subscales on the strengths and difficulties questionnaire (SDQ): data from British parents, teachers and children. J Abnorm Child Psychol. 2010;38(8):1179-91.

64. Boyce $\mathbf{W}$, Torsheim T, Currie C, Zambon A. The family affluence scale as a measure of national wealth: validation of an adolescent self-report measure. Soc Indic Res. 2006;78(3):473-87.
65. StataCorp L. Stata 13. StataCorp LP., College Station, Texas, United States. http://www.stata.com; 2013.

66. Campbell R, Starkey F, Holliday J, Audrey S, Bloor M, Parry-Langdon N, Hughes R, Moore L. An informal school-based peer-led intervention for smoking prevention in adolescence (ASSIST): a cluster randomised trial. Lancet. 2008;371(9624):1595-602.

67. Audrey S, Cordall K, Moore L, Cohen D, Campbell R. The development and implementation of a peer-led intervention to prevent smoking among secondary school students using their established social networks. Health Educ J. 2004;63(3):266-84.

68. Audrey S, Holliday J, Campbell R. It's good to talk: adolescent perspectives of an informal, peer-led intervention to reduce smoking. Soc Sci Med. 2006; 63(2):320-34.

69. Clark C, Haines MM, Head J, Klineberg E, Arephin M, Viner R, et al. Psychological symptoms and physical health and health behaviours in adolescents: a prospective 2-year study in East London. Addiction. 2006; 102(1):126-35.

70. Kimm SY, Glynn NW, Obarzanek E, Kriska AM, Daniels SR, Barton BA, Liu K. Relation between the changes in physical activity and body-mass index during adolescence: a multicentre longitudinal study. Lancet. 2005; 366(9482):301-7.

71. Page AS, Cooper AR, Griew P, Jago R. Children's screen viewing is related to psychological difficulties irrespective of physical activity. Pediatrics. 2010; 126(5):e1011-7.

\section{Publisher's Note}

Springer Nature remains neutral with regard to jurisdictional claims in published maps and institutional affiliations.

\section{Ready to submit your research? Choose BMC and benefit from:}

- fast, convenient online submission

- thorough peer review by experienced researchers in your field

- rapid publication on acceptance

- support for research data, including large and complex data types

- gold Open Access which fosters wider collaboration and increased citations

- maximum visibility for your research: over $100 \mathrm{M}$ website views per year

At BMC, research is always in progress.

Learn more biomedcentral.com/submissions 